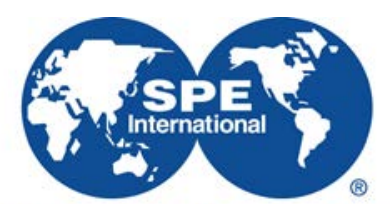

Society of Petroleum Engineers

\title{
SPE-196818-MS
}

\section{Complex Approach for Gas Lift Wells Optimization for Orenburgskoe Field}

\author{
Eugene Kapusta, Gazpromneft-Orenburg; Konstantin Rymarenko, SIANT; Marat Nukhaev, Siberian Federal \\ University; Sergey Grishenko, Galymzhan Aitkaliev, Daniil Minin, Vasily Kabanov, Denis Galkin, and Tatyana \\ Karamysheva, SIANT; Vladimir Ulyanov, Gazpromneft; Nikita Dadakin, Siberian Federal University
}

Copyright 2019, Society of Petroleum Engineers

This paper was prepared for presentation at the SPE Russian Petroleum Technology Conference held in Moscow, Russia, 22 - 24 October 2019.

This paper was selected for presentation by an SPE program committee following review of information contained in an abstract submitted by the author(s). Contents of the paper have not been reviewed by the Society of Petroleum Engineers and are subject to correction by the author(s). The material does not necessarily reflect any position of the Society of Petroleum Engineers, its officers, or members. Electronic reproduction, distribution, or storage of any part of this paper without the written consent of the Society of Petroleum Engineers is prohibited. Permission to reproduce in print is restricted to an abstract of not more than 300 words; illustrations may not be copied. The abstract must contain conspicuous acknowledgment of SPE copyright.

\section{Abstract}

At the moment in Russia, the gas-lift method of operation is becoming popular again not only because of the significant reduction in operating costs, ease of operation, but because of the involvement in the development of a large number of assets with oil rims. This paper describes an integrated approach to optimizing the operation of wells in the Orenburg oil and gas condensate field, which is characterized by the largest number of wells in Russia that are operated by gas lift. The paper describes traditional approaches to the gaslift well testing as well as a new approach to improve operational efficiency.

\section{Features of gas lift wells operation at the Orenburg oil and gas condensate field}

Orenburg oil and gas condensate field is the largest oil and gas reserves in the region. The deposit is confined to the Orenburg shaft, which is located in the extreme northern highest part of the Sol-Iletsky arch.

The Orenburg oil and gas condensate field was discovered in 1966 by Krasnokholmskaya exploration well number 13. The Artinsko-Middle Carboniferous oil rim was discovered in the early 1970s. Oil rim oil reserves were first calculated in 1981. A systematic study of the oil deposits of the Eastern section began in the late 1980s. In 1994, the oil rim of the Eastern section was put into pilot development.

The field is in the process of active oil production. The increase in oil production is caused by the annual commissioning of new drilled production wells.

The main geological complications and uncertainties in the Eastern Section of the Orenburg oil and gas condensate field are (Galyautdinov, 2017):

- low permeability (less than 1 micron2)

- the presence of cracks and faults

- uneven distribution of fracture in the area

- high variability of filtration and capacitive properties over the area 
- the presence of a massive gas cap (in the main part of the reservoir, gas and oil saturated thicknesses reach $30-50 \mathrm{~m}$ )

- high $\mathrm{H} 2 \mathrm{~S}$ content.

High gas factor and $\mathrm{H} 2 \mathrm{~S}$ content (up to 6\%) in the production of oil wells determined the main method of operation - natural flow with the subsequent transition to gas lift. Currently, more than 300 production wells are in operation. According to the method of operation, the operating production wells are distributed as follows. More than $70 \%$ of the operating oil producion wells are operated by gas-lift method, almost $10 \%$ are equipped with ESP and about $20 \%$ of the wells produce oil using the natural flow method. More than $90 \%$ of wells work with a water cut of no more than $3 \%$.

Until recently, at the Orenburg oil and gas condensate field, a natural gas lift system was used. The essence of this method is shown in Figure 1. A gas producion well, drilled either into a gas cap or into a gas formation, supplies a gas collector with gas-lift gas. A gas reservoir distributes gas-lift gas to a specific number of oil producion wells (usually producion wells located on the same well pad). The gas lift gas, as well as during traditional gas-lift operation, is pumped into the annulus of production wells and flows through the gas-lift valves into the tubing to reduce the density in the tubing string, thus allowing the well to work. The undoubted advantage of this modification is a significant reduction in capital costs (the cost of building a compressor and other surface facilities) and operating costs (electricity). At the same time, as a gas production well, it is possible to use both new wells drilled in the gas cap, and production wells in which a gas breakthrough occurred (Trubavin, 2017).

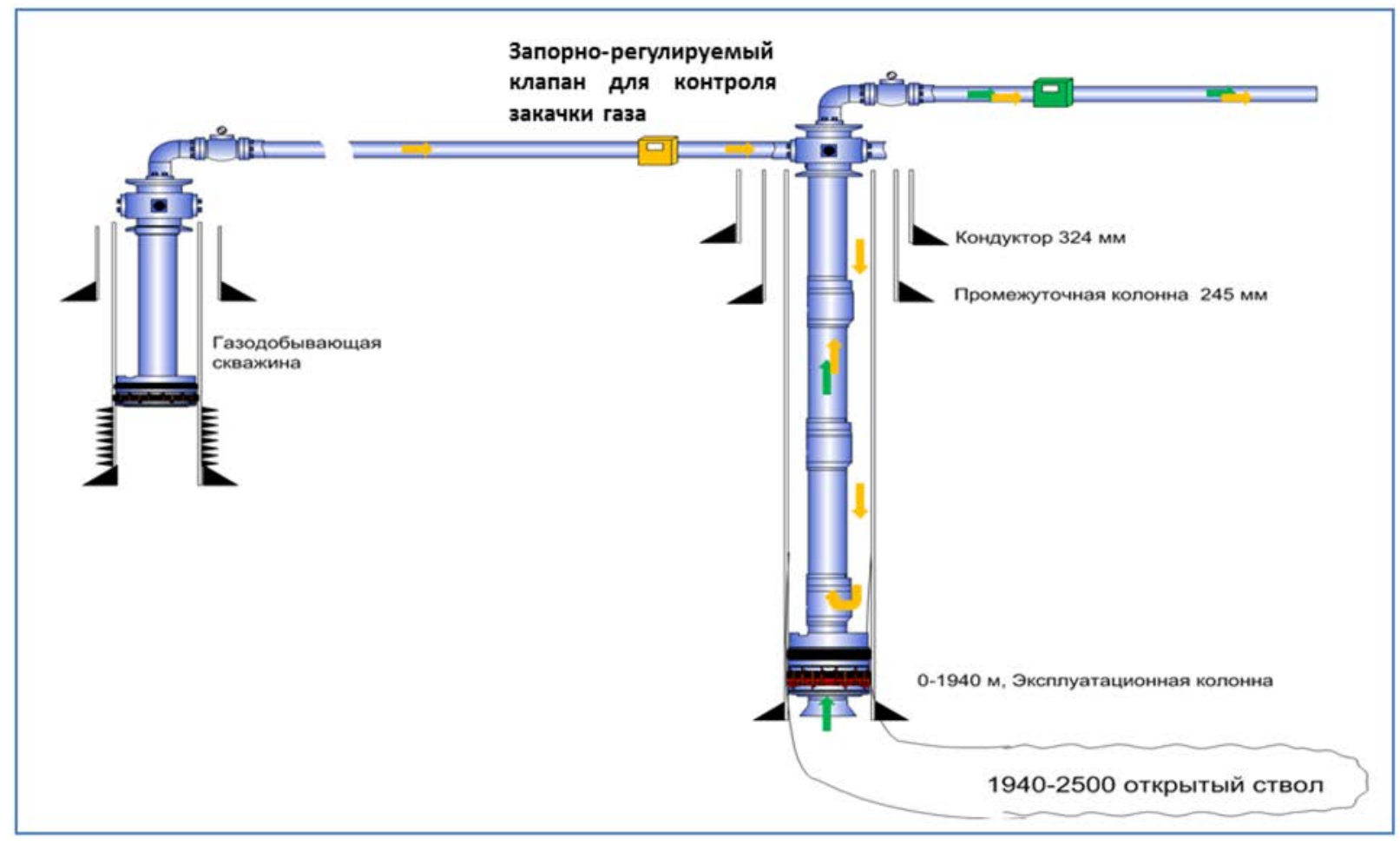

Figure 1-Diagram of a natural gas lift.

As the gas production wells are depleted and in order to optimize gas recovery and utilization, and to preserve the energy potential of the reservoir, it has become necessary to switch from a natural gas lift to a classical scheme using compressors. Less than a year ago, this project was implemented, which made the development of the Eastern section of the Orenburg oil and gas condensate field a benchmark in the field of field development in a gas-lift way: today there are no gas-lift production implementation projects 
comparable in scale in Russia. Within the framework of this project, a unique experience of well operation has been accumulated in the natural flow, ESP and in two ways (natural and classical) gas-lift production. The launch of the classic gas-lift scheme led to serious changes in the injection system and the initial unbalance of the previously set gas-lift system. The increase in pressure led to an increase in the content of liquid hydrocarbons and hydrates in the gas-lift gas supply The increase in pressure in the gas supply system, providing a higher energy for lifting liquid from the bottom, revealed a number of difficulties associated with non-optimal tuning of elevator systems: gas circulation through gas-lift starting valves increased the mutual influence of production wells on each other, caused a "blocking" of the collection system and negatively reflect at work producing wells. The identification of these problems and their elimination required the development of new technologies and approaches to data analysis and well management. The development of monitoring and control methods required the development of new approaches both in algorithms and methods for measuring gas injection rates and their control, as well as the development of new flowmeters designed for high content of liquid and solid components in the flow specifically for the Orenburg oil and gas condensate field conditions.

The main volume of oil production in 2015-2016 (63\%) was provided by wells operated by the natural gas-lift method, about $23 \%$ of the annual volume was produced by wells operating by the natural low method. The minimum production was from wells equipped with ESP, their share in annual volume was $14 \%$. Today, the majority of wells in the field are operated using compressed gas using the classical gas-lift method. This made it possible to increase control over the operational parameters of each well significantly, to provide a much wider range of pressures for the injection of gas-lift gas, to get rid of dependence on the operating modes of gas production wells, and to ensure an increase in production from remote end wells.

A feature of the gas-lift method of operation is the need for continuous monitoring of injection into each well individually. This is caused by the fact that a gas production or compressor well provides gaslift gas to groups of producing oil wells, whose operating parameters may differ significantly from each other (flow rates, bottomhole pressure, gas factor, water cut, etc.). Thus, for each well there are optimal injection parameters, which also vary with time depending on changes in the parameters of the well, well cluster or field.

Therefore, by controlling these parameters (gas lift gas flow rate), it is possible to increase the efficiency of gas lift operation significantly not only of individual wells, but also of well clusters. At the same time, it is possible to reduce gas consumption and deal with problems of hydrate formation at the wellhead.

To improve the efficiency of well operation in the Orenburg oil and gas condensate field, first pilot tests were carried out, and then the full scale implementation of the Gazlift automated process control system began (Ulyanov, 2018). This system is designed to control the process of gas-lift oil production by remotely controlling of cluster automatic systems of the Gaslift automated process control system, including:

- collection and processing of information from primary transducers

- control of actuators to ensure optimal well performance

- operational change of well operation mode

- accumulation of the obtained information for the statistical data and monitoring of the state of oil wells.

The system consists of two main parts: the regulation unit -seat control valve, shown in Figure 2 and the automation unit. The regulation unit is connected via a bypass to the gas-lift gas injection line. With this piping scheme, it is possible to work either directly without controlling the injection rate, or through a regulation unit with fixation of all the operating parameters of the well. The regulation unit is an electrically operated needle valve that allows fine adjustment of the gas flow or maintaining a certain injection pressure, regardless of the pressure in the gas line. The control of the regulation unit, control of work, as well as data 
transfer occurs using the automation unit. The following data is transmitted and visualized to the automation unit from each well on the control panel: pressure and temperature before regulation unit, pressure and temperature after regulation unit, valve flow area, current gas flow rate (or pressure) through regulation unit, culculated gas rate. Also, the measurements wellhead pressure, annulus pressure and line pressure are additionally connected. This data allows you to process input data in real time, change the valve flow area of the the regulation unit to maintain the flow rate or constant pressure of gas injection to optimize the operation of the gas lift.

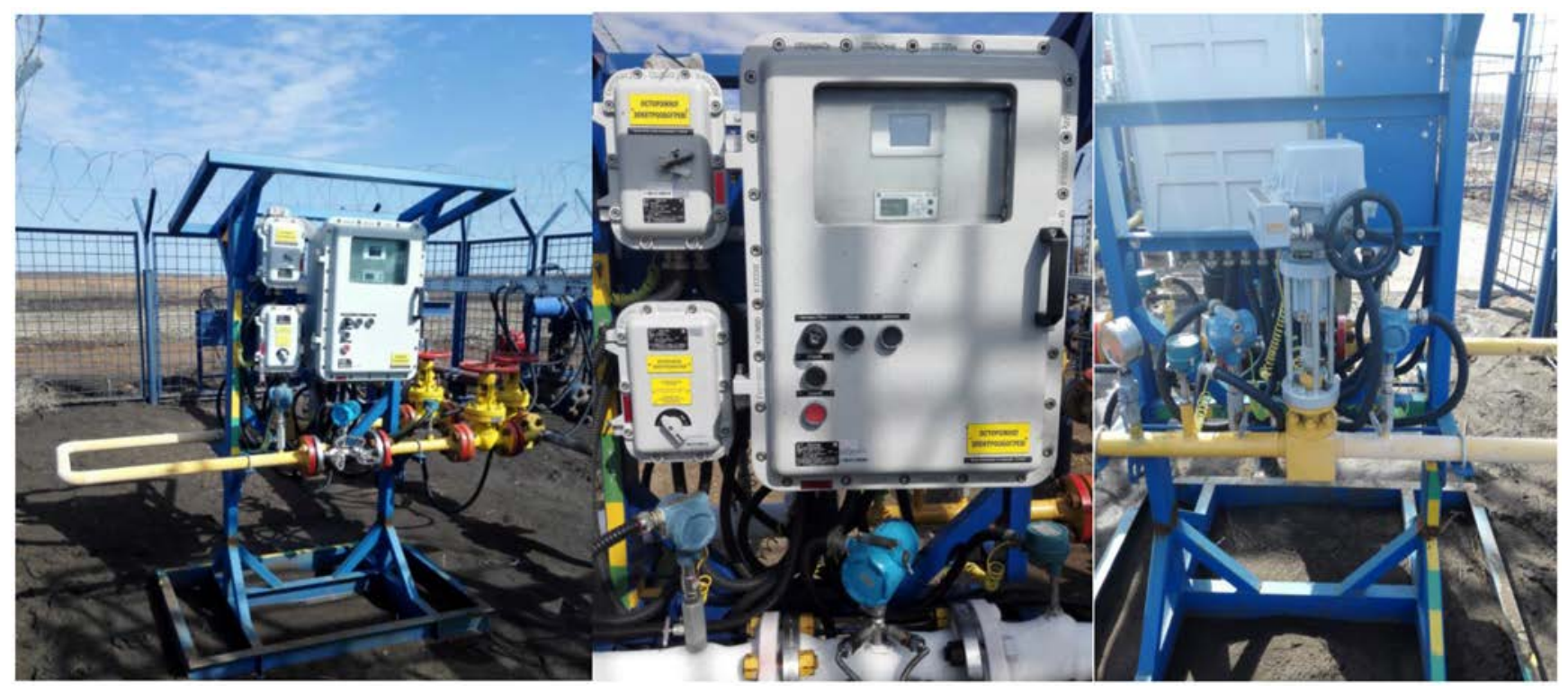

Figure 2-Gaslift automated process control system

The full scale implementation of the Gazlift automated process control system allows GazpromneftOrenburg not only to optimize the operation of the gas-lift wells, but also to optimize the whole work at the field, by:

- freeing up time for engineers to analyze and make decisions by reducing the workload for routine operations

- optimization of operators work due to remote control of technological objects and wells

- reducing the risks of occupational safety and health of personnel in conditions of high content of hydrogen sulfide.

\section{Necessity of well testing for gas lift optimisation}

In gas lift operation, the optimal well operation mode is achieved under the following conditions:

- the gas injection point is located at the maximum possible depth

- gas is injected through one working gas-lift valve

- gas flow rate is selected to ensure minimum bottomhole pressure and maximum flow rate or minimize the specific flow rate of injection gas per $1 \mathrm{~m} 3$ of fluid.

However, in practice, the mode of operation may vary. The use of common nodal analysis programs for gas-lift wells that deviate from the regime and the selection of new layouts, as a rule, requires a complete set of well data. The same requirement is imposed if it is necessary to build an integrated model, which includes not only the work of wells, but also the work of surface facilities and the network of pipelines. 
Thus, the following well studies are traditionally used to optimize gas-lift wells:

- pressure stabilization curve (for fixing the bottomhole pressure value at a certain mode of operation of the well)

- thermometry to determine the tightness of the tubing and confirm the operation of the gas lift only through a working gas lift valve (this study is very important for the wells of the Orenburg oil and gas condensate field due to the high content of $\mathrm{H} 2 \mathrm{~S}$ (up to $6 \%$ ) in formation fluid and gas lift gas)

- measurements of gas-lift gas injection for each well operation mode

- well flow rate measurements for multiphase fluid for each well operation mode

- measurements of annular pressure and wellhead pressure to characterize the modes of well operation.

Data of bottomhole pressure and thermometry are obtained in the process of well investigation with the help of the descent of an autonomous pressure gauge on a wire. The main factor of success in conducting such well studies is not only the condition for the well to reach a steady-state mode of operation and correct measurement of the corresponding bottomhole pressure, but also measurements along the wellbore (above and below the unloading gas-lift valves). These measurements make it possible to construct not only pressure and temperature profiles along the wellbore, but also the density profile of the well fluid.

Measurements of the annular and wellhead pressures at the gas-lift wells of the Orenburg oil and gas condensate field are automated and transmitted through the Gazlift automatic process control system (Ulyanov, 2018). But according to the measurements of gas-lift gas and multiphase well production there were certain issues. Traditionally, well flow rates at the Orenburg oil and gas condensate field are measured using group automatic devices for measuring well production based on three-phase gravity separators. The main functionality of these metering installations are:

- automatic switching of wells to metering

- automatic measurement of the flow rate of wells connected to group metering units

- control over the operation of wells by the presence of fluid supply

- automatic blocking of wells in emergency condition.

The main disadvantages of group metering installations include the inability to provide 24 hour metering of all wells, and the fact that switching to metering changes the well operation status (mode of operation) and requires a certain time for the well to reach the established mode of operation. For example, in gaslift well surveys in 2016, it was shown that it takes 12-14 hours to establish the mode (Figure 3). Accordingly, traditional two-hour measurements (to measure the entire well cluster) are not suitable for conducting gas lift wells. 


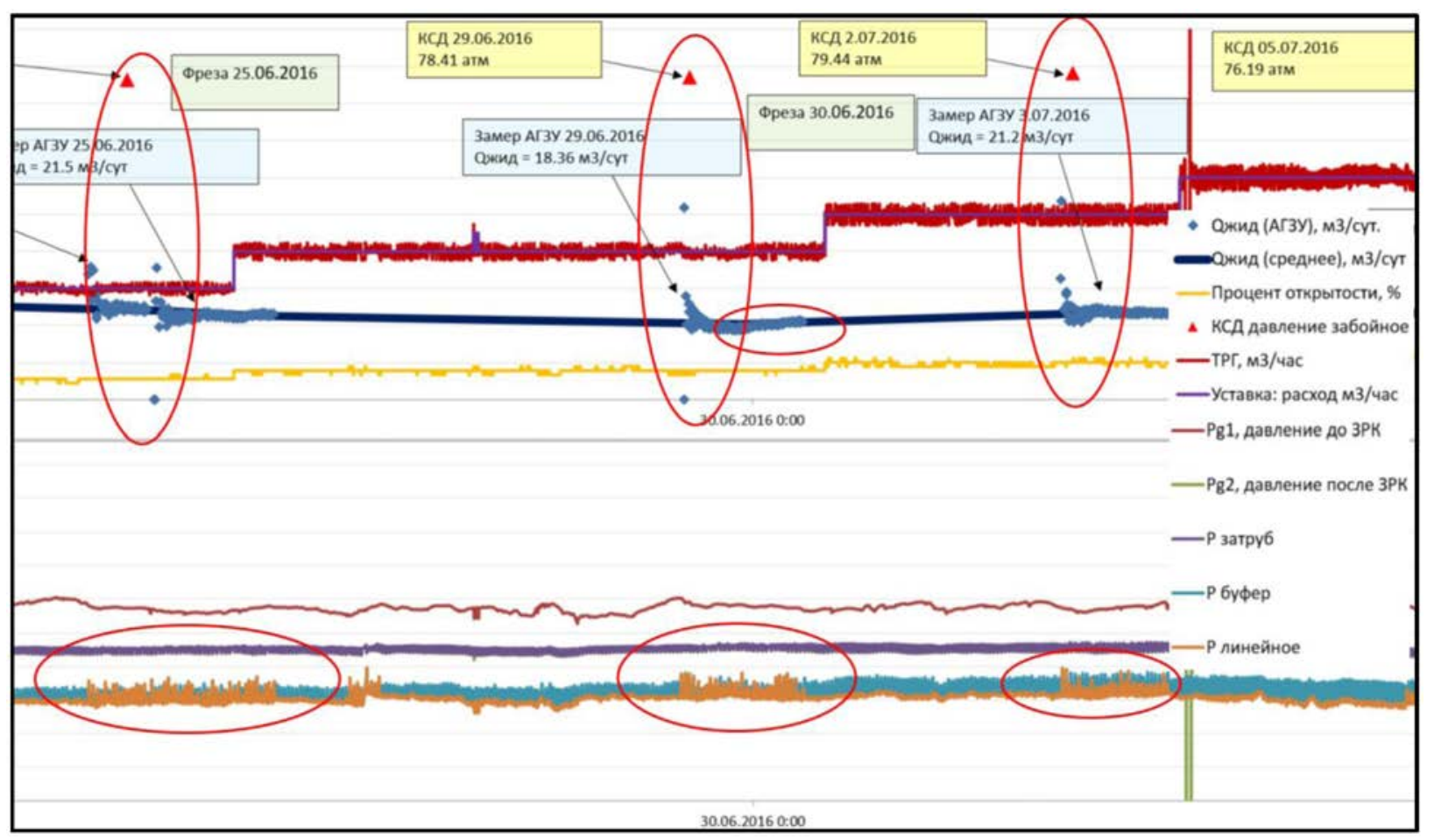

Figure 3-Gas lift well surveys using group metering unit

It was decided to use multiphase flow metering technology to conduct research at gas-lift wells of the Orenburg oil and gas condensate field. The tasks of multiphase flow metering are reduced to estimating the total mass flow rate of fluid passing through the device, estimating the flow of each of the individual phases of the fluid through the instrument section, estimating the speeds of each phase and, thus, estimating the flow rates of the individual phases in linear conditions. Further, using information on the PVT properties of the measured fluid, the flow rates are obtained under standard conditions. In the most of known devices, the task of estimating the mass flow rate of a multiphase fluid is solved by measuring the pressure drop across a restriction device. The pressure drop measured by high-precision manometers is recalculated into the mass flow rate of a multiphase flow according to Bernoulli law, taking into account various speeds and phase slip relative to each other. For example, in the Vx technology today, a Venturi pipe vertically to the flow is used as a restriction device (Figure 4). The vertical arrangement greatly simplifies the structure of a multiphase flow, saving it from gravitational segregation in a section perpendicular to the flow direction. 


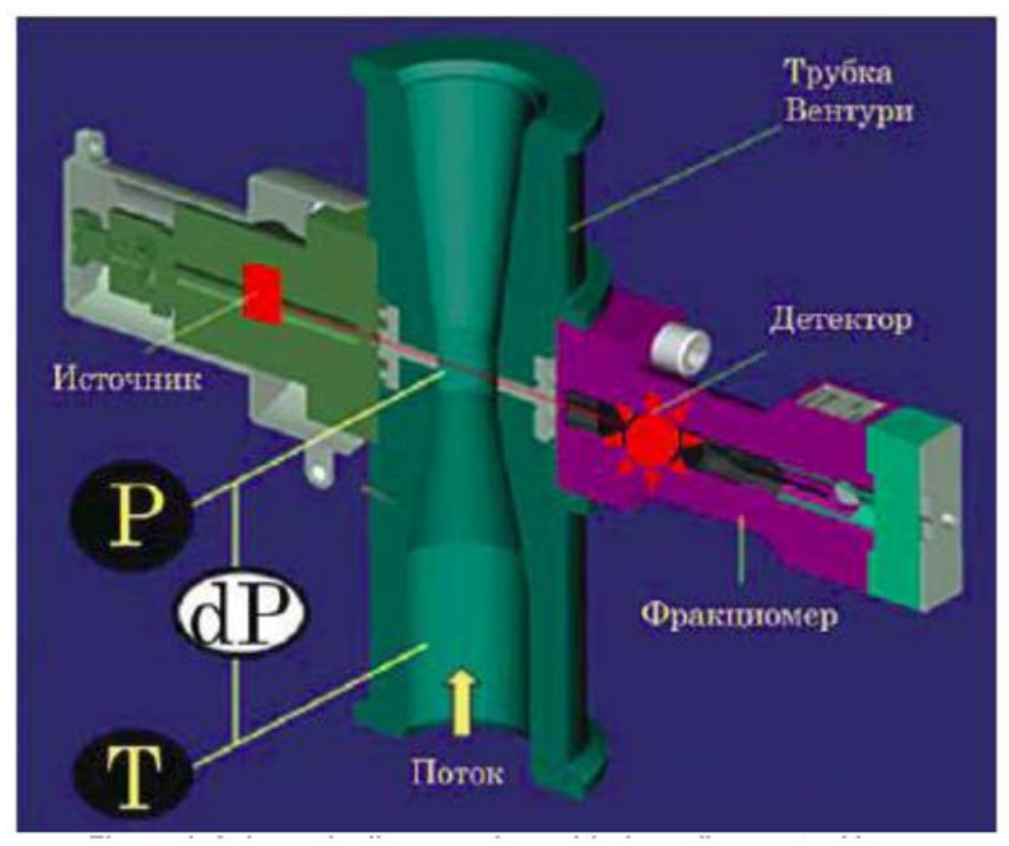

Figure 4-Schematic diagram of a multi-phase flow meter Vx

Figure 4 shows the principle of operation of a multi-phase flow meter that implements Vx technology. Multiphase flow passes upwards through a vertical Venturi. The pressure drop across the restriction device allows to estimate the mass flow rate of the fluid passing through the system. In addition to the pressure drop, the values of linear pressure and temperature are constantly recorded. Then, having basic information about the properties of reservoir fluid (viscosity and density, which are determined directly on samples of the well fluid in the field) and mass flow, it is necessary to determine the individual flow rates of each phase in linear conditions. The flow rate of each phase is determined by its speed and cross-sectional area in the Venturi tube. The cross-sectional area of each fraction is determined using a radioactive source and a receiver-fractionator (Figure 4). The fractioner operation principle is to assess the absorption spectrum of various types of fluid at different energy levels. Thus, a flowmeter with a radioactive source provides good resolution for flow measurements for all phases of the measured fluid. In Russia, multiphase flow metering is used in both gas condensate wells and high-viscosity oil fields (Aksenov, 2013).

Ultrasonic flow meters are traditionally used to measure gas-lift gas flow rates at the Orenburg gas condensate field (both in stationary version and overhead (Figure 5)).

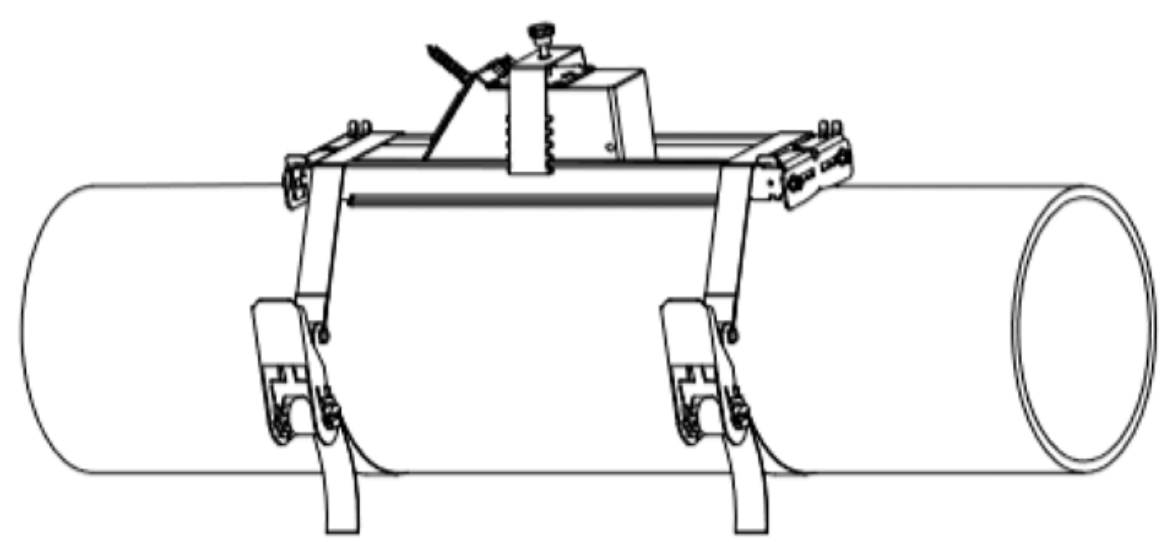

Figure 5-Surface mounted ultrasonic flow meter 
Such flowmeters measure the difference in the time of passage of an ultrasonic wave in the direction and against the direction of flow of a liquid or gas. The principle of operation of ultrasonic flow meters is based on measuring the difference in the time of passage of a signal. In this case, two ultrasonic sensors, located diagonally opposite each other, function alternately as a transmitter and receiver. Thus, the acoustic signal, alternately generated by both sensors, is accelerated when directed downstream and slows down when directed upstream. In this way, it is possible to find the average flow rate along the signal path, on the basis of which the volume flow can then be calculated under operating conditions (pressure and temperature for a given fluid composition). To compensate for the distortion of the flow profile, several acoustic channels are used. At the same time it works well only for a clean stream or a stream with a low content of suspended particles.

This type of flowmeter is limited for the operating conditions of wells in the Orenburg oil and gas condensate field due to the fact that a part of the wells uses pressureless gas lift. With this method of operation, gas from the donor well does not go through dehydration and is supplied as gas-lift gas to the production wells along with drops of liquid hydrocarbons and water. Also, the influence of a sharply-continental climate is coalesced, when daily temperature fluctuations reach $40^{\circ} \mathrm{C}$, which leads to condensation.

When conducting well surveys, the situation is aggravated by a change in the operating modes of the well and a corresponding change in the operating modes of the gas lift gas supply line. When changing the gas-lift gas flow rate, the pressure wave disrupts condensate droplets from the pipe walls, which leads to an increase in the proportion of liquid in the flow. Figure 6 shows the indications of a commercial ultrasonic flow meter when conducting research on gas-lift wells in 2016. As shown in this Figure 6, fluctuations in the readings of the ultrasonic flow meter after changing the operating mode of the wells reach $+/-50 \%$ $-75 \%$ of the setpoint value.

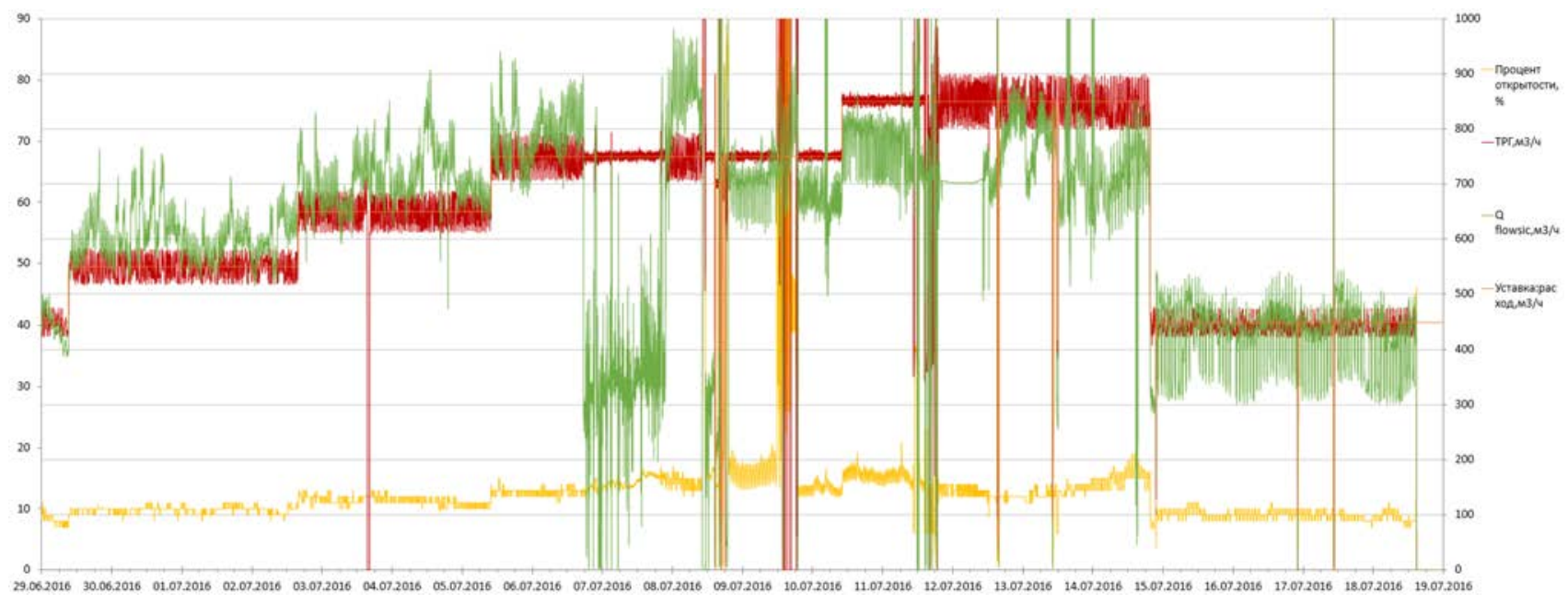

Figure 6-Gas-lift gas flow measurements with an ultrasonic flow meter

As an alternative, it was proposed to use calculated flow rate of gas-lift gas, obtained by recalculating from valve position data in the Gas-lift automated process control system (cross-sectional area), pressure drop and temperature data. Figure 7 presents a comparison of ultrasonic flow meter and calculated flow rate of gas-lift gas data in one of the gas lift wells during the study. The research cycle consisted of steps 5-10-15-20-17-14-11-8\% valve opening, each of which lasted 60 minutes. As shown in Figure 7 calculated flow rate of gas-lift gas fits into the middle line of the ultrasonic flow meter at its noisy values.

Thus, the purpose of the research is to build the dependence of the bottomhole pressure and the corresponding flow rate of the fluid on the flow rate of the injection gas through the working valve (Figure 
8) (Shushakov, 2015). This will allow to find the optimal gas-lift gas flow rate for each well and to maintain this injection using the Gas-lift automated process control system.

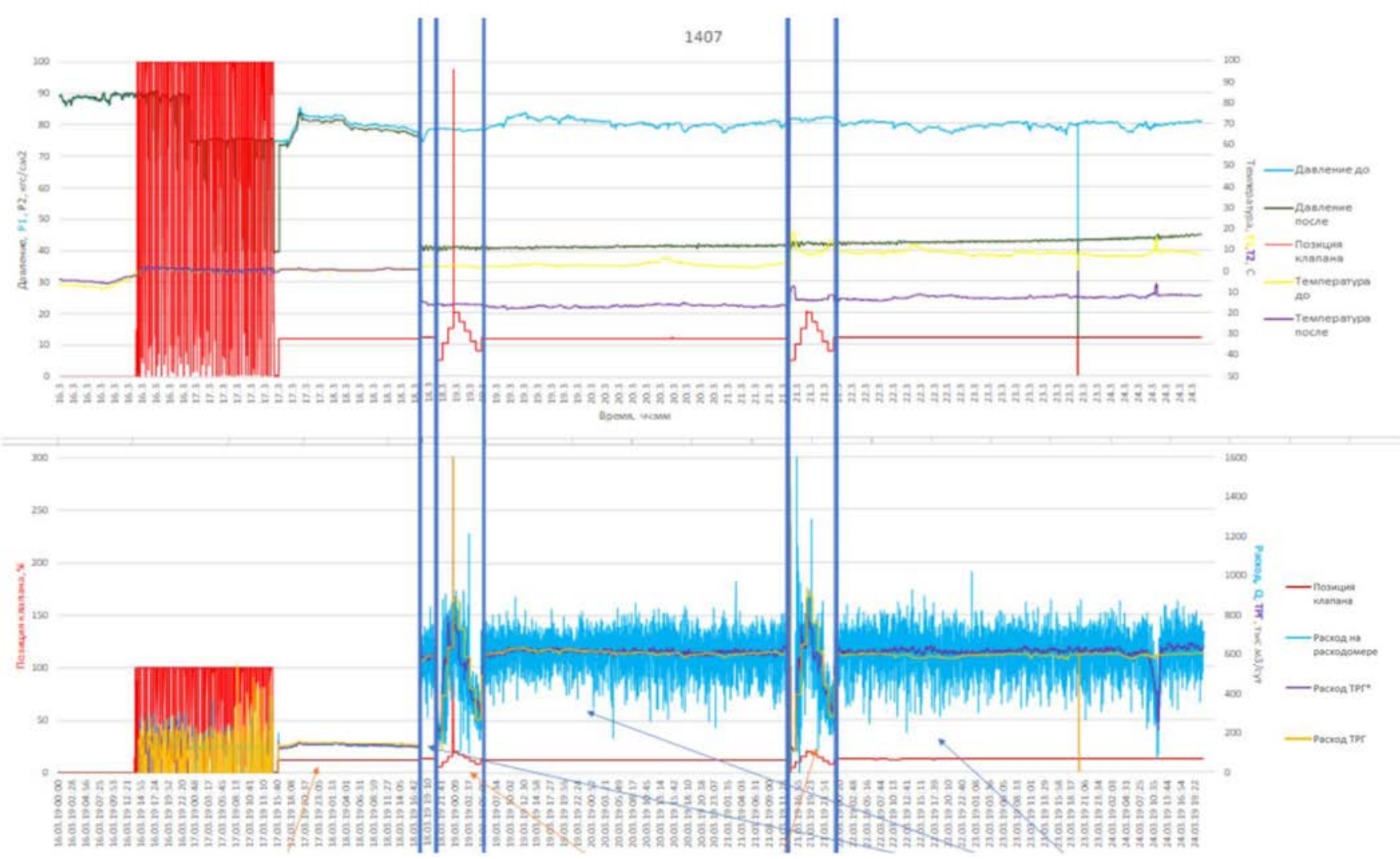

Figure 7-Comparison of ultrasonic flow meter and calculated flow rate of gas-lift gas

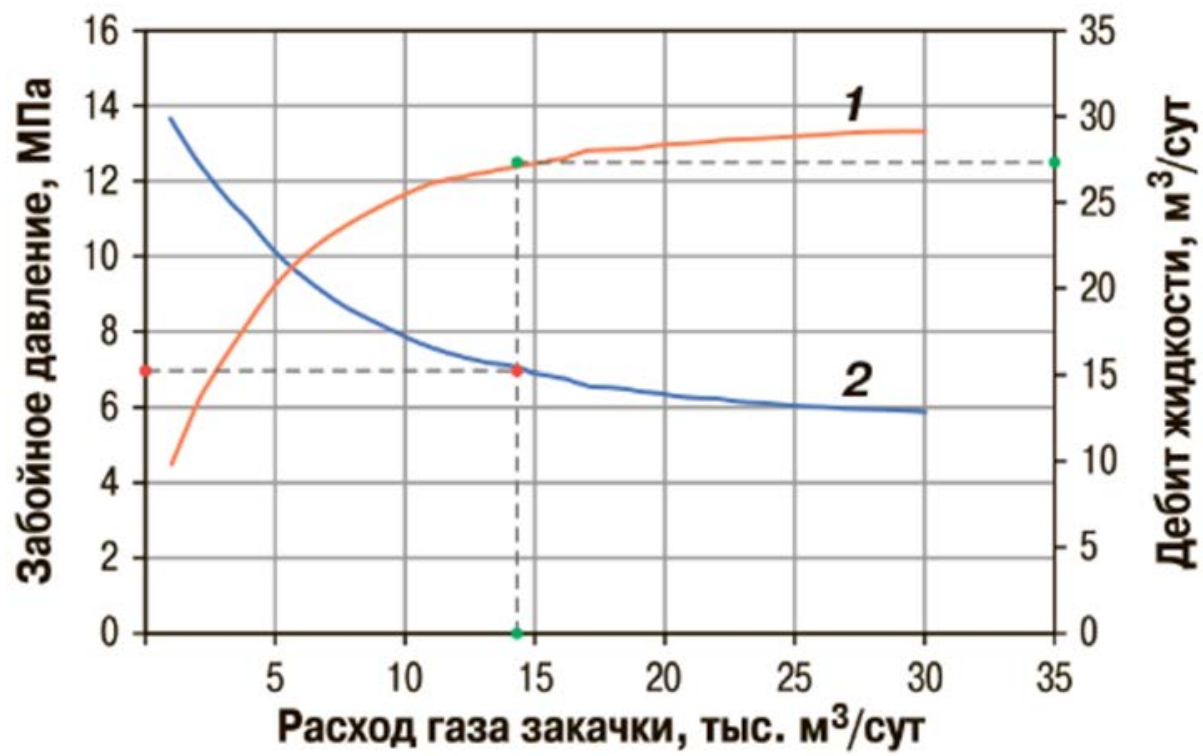

Figure 8-The dependence of the bottomhole pressure and the corresponding flow rate of the liquid from the gas rate 


\section{Well testing of the gas lift wells}

To conduct research on the gas-lift wells of the Orenburg oil and gas condensate field, an experimental field was selected and studies were successively carried out on a certain number of wells. The following describes the steps and presents a research program for one of the typical wells.

The completion scheme of a typical gas-well of the Orenburg oil and gas condensate field is shown in Figure 9. Injection mandrels (gas-lift mandrels) of $73 \mathrm{~mm}$ with gas-lift valves are installed at depths of 600 , 1200, 1810 meters. Circulating valves are also installed above and below the packer.

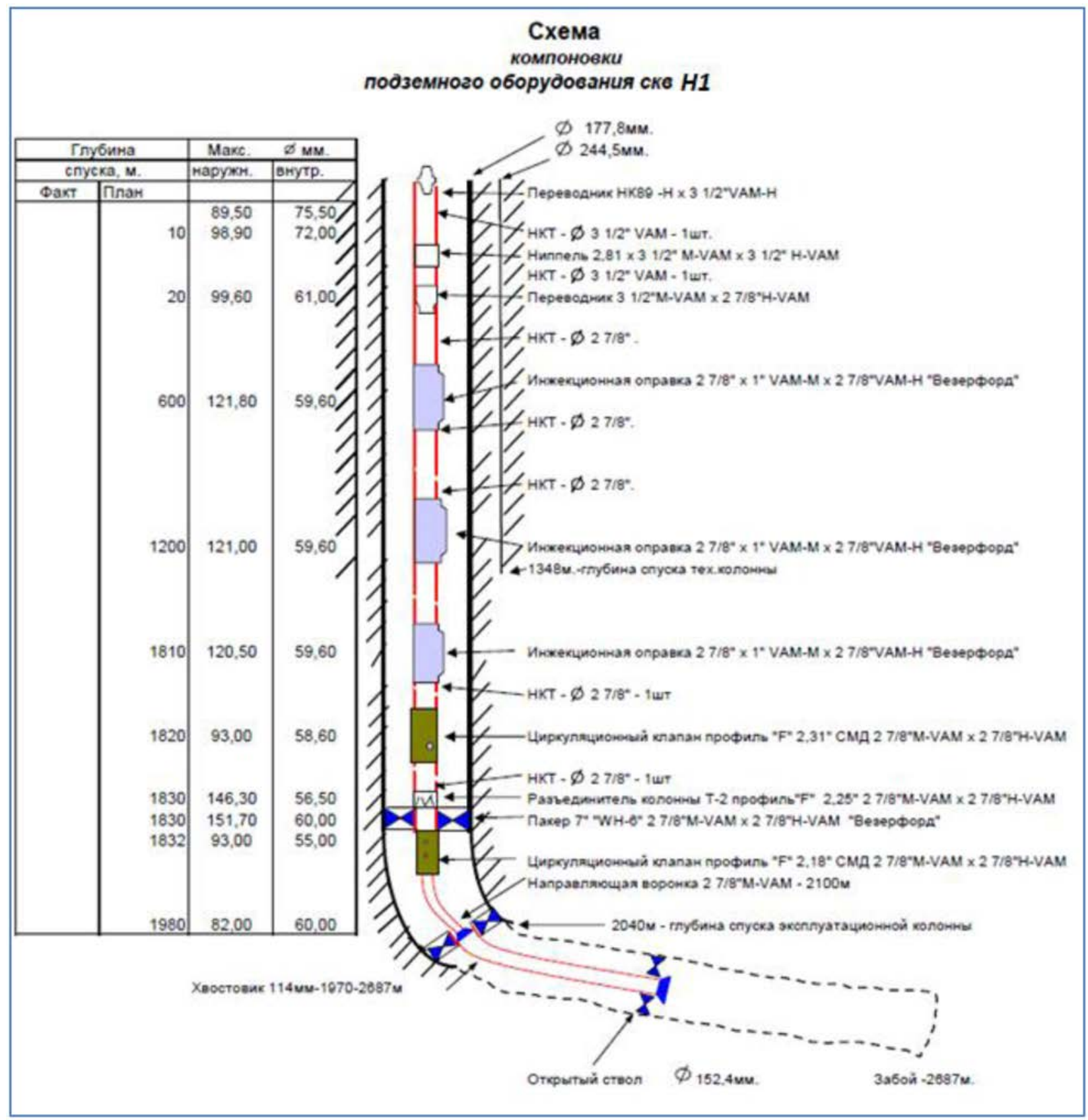

Figure 9-Scheme of completion of a typical gas-lift well of the Orenburg oil and gas condensate field 
The general research program of gas-lift wells is divided into 2 parts:

1. Testing the well on 2 regimes ( 2 oil fittings) at a fixed current gaslift gas injection pressure

2. Testing the well at the current oil fitting $(18 \mathrm{~mm})$ with a change in flow area on the process control system - an increase in pressure and pumping gas-gas gas -2 regimes (Table 1)

Table 1-Gaslift Well Testing Program

\begin{tabular}{|l|c|c|c|c|}
\hline $\begin{array}{l}\text { Well } \\
\text { number }\end{array}$ & $\begin{array}{l}\text { Flow } \\
\text { regime } \\
\text { number }\end{array}$ & Choke & Gas lift injection pressure & Target gas injection rate \\
\hline & & $\mathrm{mm}$ & $\mathrm{atm}$ & $\mathrm{m} 3 / \mathrm{hr}$ \\
\hline $\mathrm{H} 1$ & 1 & 18 & 49.5 & 400 \\
\hline $\mathrm{H} 1$ & 2 & 10 & 49.5 & 400 \\
\hline $\mathrm{H} 1$ & 3 & 18 & $\begin{array}{l}\text { In accordance with the setting } \\
\text { for gas-lift gas consumption }\end{array}$ & 625 \\
\hline $\mathrm{H} 1$ & 4 & 18 & $\begin{array}{c}\text { In accordance with the setting } \\
\text { for gas-lift gas consumption }\end{array}$ & 1000 \\
\hline
\end{tabular}

The technology of measurement for this type of research is as follows:

1. Settlement of a mobile metering installation of multiphase flow metering (Figure 10), designed to measure the following indicators of the production rate of oil producing wells: - mass flow rate

๑il mass flow rate

volumetric flow rate of associated petroleum gas with reduction to standard conditions.

2. Pressure testing of a complex of equipment for a pressure not less than $10 \%$ higher than the maximum expected.

3. Check all sensors, power source and gamma source energy levels. Zero setting on the differential pressure sensor. Calibration of a restriction device on an empty pipe.

4. Sampling of oil and water from the well fittings and the subsequent determination of the reference phase points of a multiphase flow meter.

5. Installation of pressure gauges, recording in the continuous regime gas injection pressure, wellhead pressure, line pressure. Installation of ultrasonic flow meter for gas-lift gas injection with measurements every 15 minutes.

6. Transfer of the well to the $18 \mathrm{~mm}$ socket and start-up (regime 1).

7. Begin registration of gas injection pressure, wellhead pressure, line pressure, gas-lift gas flow rate at the current fitting. Registration of the flow rate of the liquid and the wellhead temperature is carried out on the metering unit of the multiphase flow metering company.

8. Production of wire well survey service (Figure 11).

9. After the well has been put into operation, the well testing is investigated by lowering the manometer and the thermometer (to record the pressure and temperature in the well). At the beginning of the descent, stops are made at a depth of 150 and $300 \mathrm{~m}$ to determine the change in temperature near the surface. Further, on the descent of the device, the stops for measurements are carried out every $300 \mathrm{~m}$ for about 3 minutes to assess the stability of the well. The depth of the descent of the device - to the extent possible to the depth of the descent of the tubing (to determine the potential accumulation of water in the wellbore, to assess the correlations with the GF). At this depth, the recording is carried out for 60-120 minutes. On the rise, stops are made for 5 minutes 
approximately $3 \mathrm{~m}$ below and above the location of each mandrel to determine the gas injection efficiency and the number of injection points.

10. Transfer of the well to the following conditional fitting by adjusting the angle throttle and launching the well into operation (regime 2).

11. Well tests according to clauses 7-9.

12. Changing the position of the regulation unit to achieve gas-lift gas consumption according to Table 1 (regimes 3). Waiting for stabilization of the operation mode (constant pressure, stable debit and gas factor).

13. Well tests according to clauses 7-9.

14. Transition to regime 4.

15. Registration of pressures at the wellhead and on the $\mathrm{g} / \mathrm{g}$ line for several days after the termination of well testing.

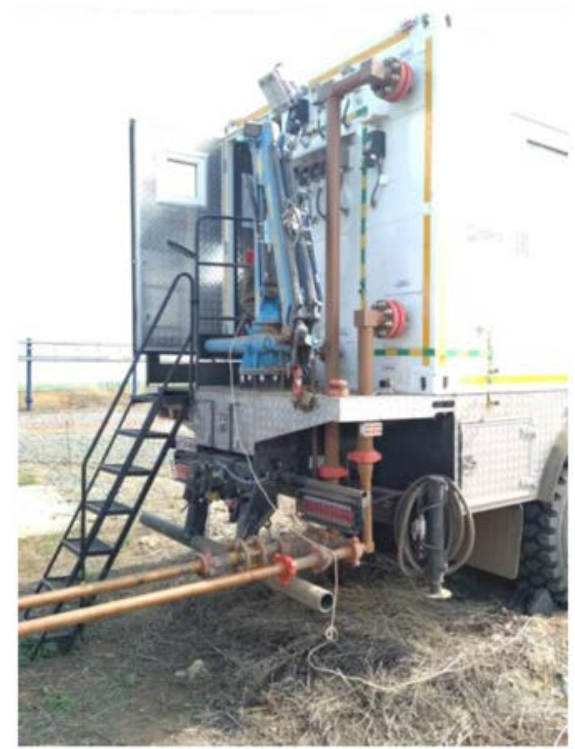

Figure 10-Mobile multiphase flow metering system

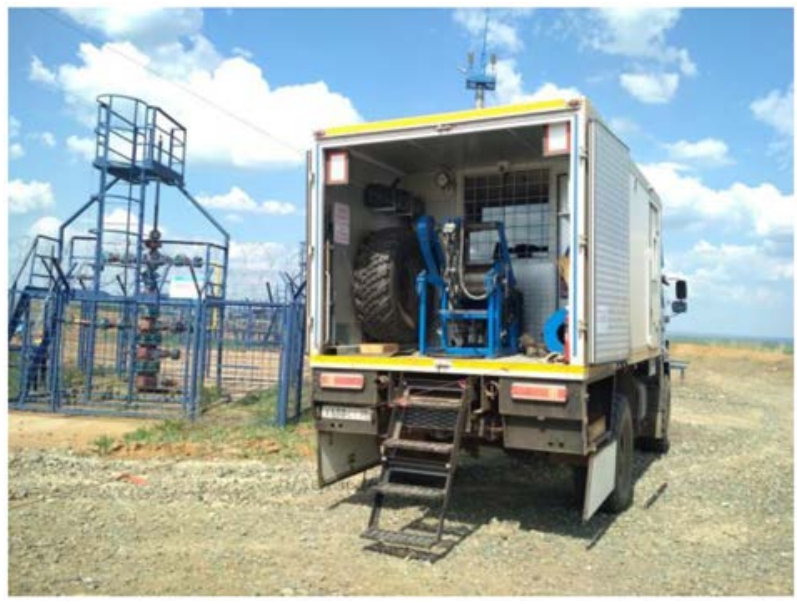

Figure 11-Well testing

The results of the study of a typical well of the Orenburg oil and gas condensate field are presented in the Appendix in Figure A-1. This figure shows the measurements of oil and gas of a mobile multiphase flow meter, data of the buffer, linear and annular pressure, as well as data of the well testing and indications 
of the automated process control system (readings pressure and temperature sensors before and after the valve, valve position and gas-lift gas flow) for all 4 well test regimes. When analyzing data, the following points should be noted:

- Pressure fluctuations in the gas-lift gas injection line reached a value of 20 atm (P1)

- Gaslift automated process control system supported gaslift gas injection parameters (P2) by changing the valve position

- The Gaslift automated process control system included, as necessary, an anti-hydrate control algorithm to purge the well

- Multiphase flow meter recorded significant changes in flow rate in each mode, even with a fixed and stable gas-lift gas supply. These changes in flow rate are related to changes in buffer pressure

- To conduct more accurate studies, it is necessary to fix the wellhead pressure at a certain value.

As a result of the testing, a characteristic of the gas-lift well operation was constructed (the dependence of the oil flow rate on the gas-lift gas injection). For this well, the optimal injection is a gas flow rate of $500 \mathrm{~m} 3 / \mathrm{hr}$.

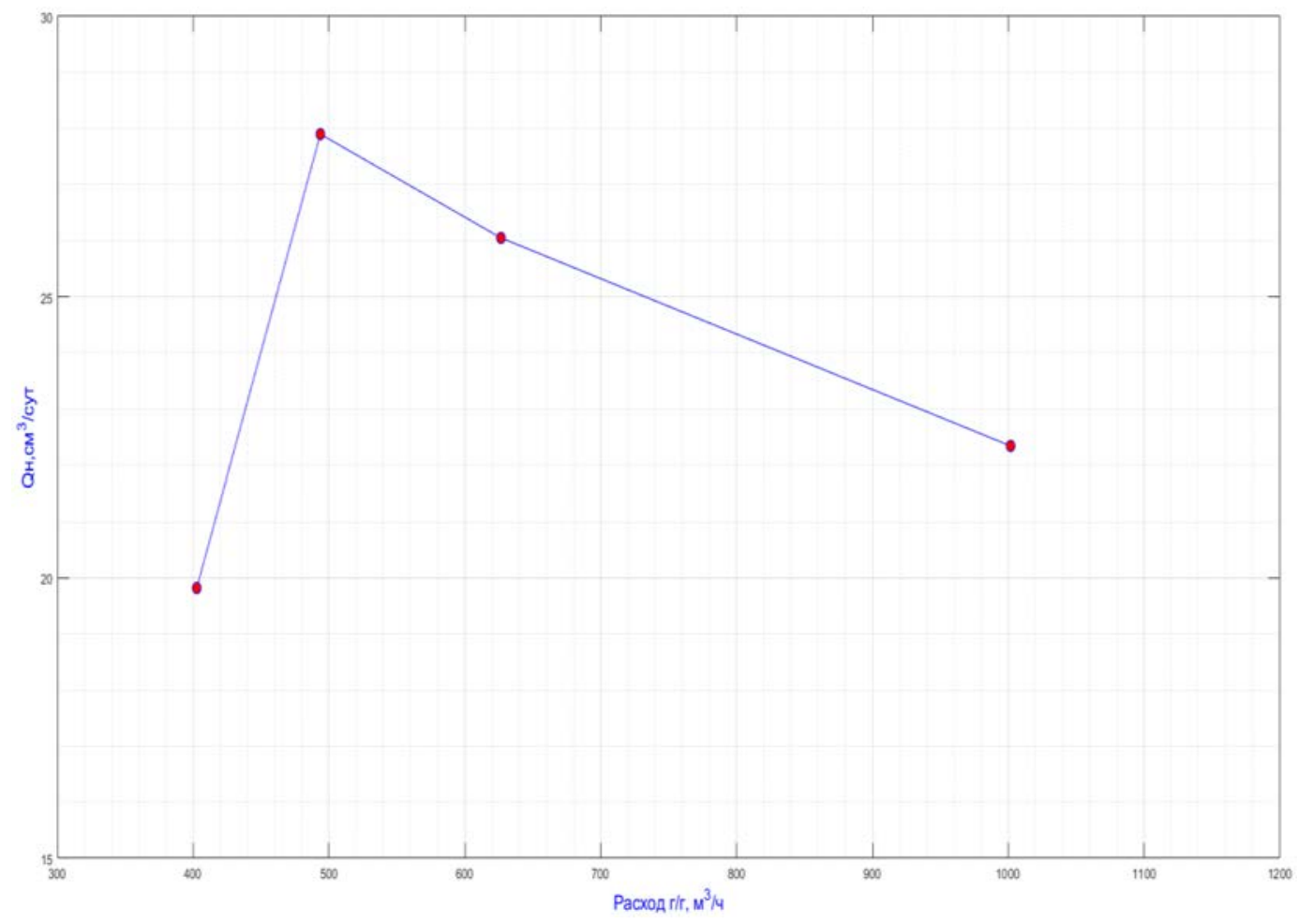

Figure 12-Well performance

The implementation of the control concept of a gas-lift well not only on the injection line, but also on the flowline is shown in Figure 13. The proposed concept allows controlling not only the gas-lift gas injection, but also the pressure on the wellhead. In addition, the well can be equipped with continuous monitoring systems on fiber-optic temperature measurement systems and downhole gauges. The implementation of this concept will allow in the automatic regime to conduct well testing and to obtain for each gas-lift well a twoparameter dependence of the fluid flow rate on gas injection and pressure at the wellhead. Therefore, by controlling these parameters with the help of an automated system (gas-lift gas consumption and pressure in the flow line), it is possible to significantly improve the efficiency of gas-lift operation of not only individual wells, but also of well clusters. 


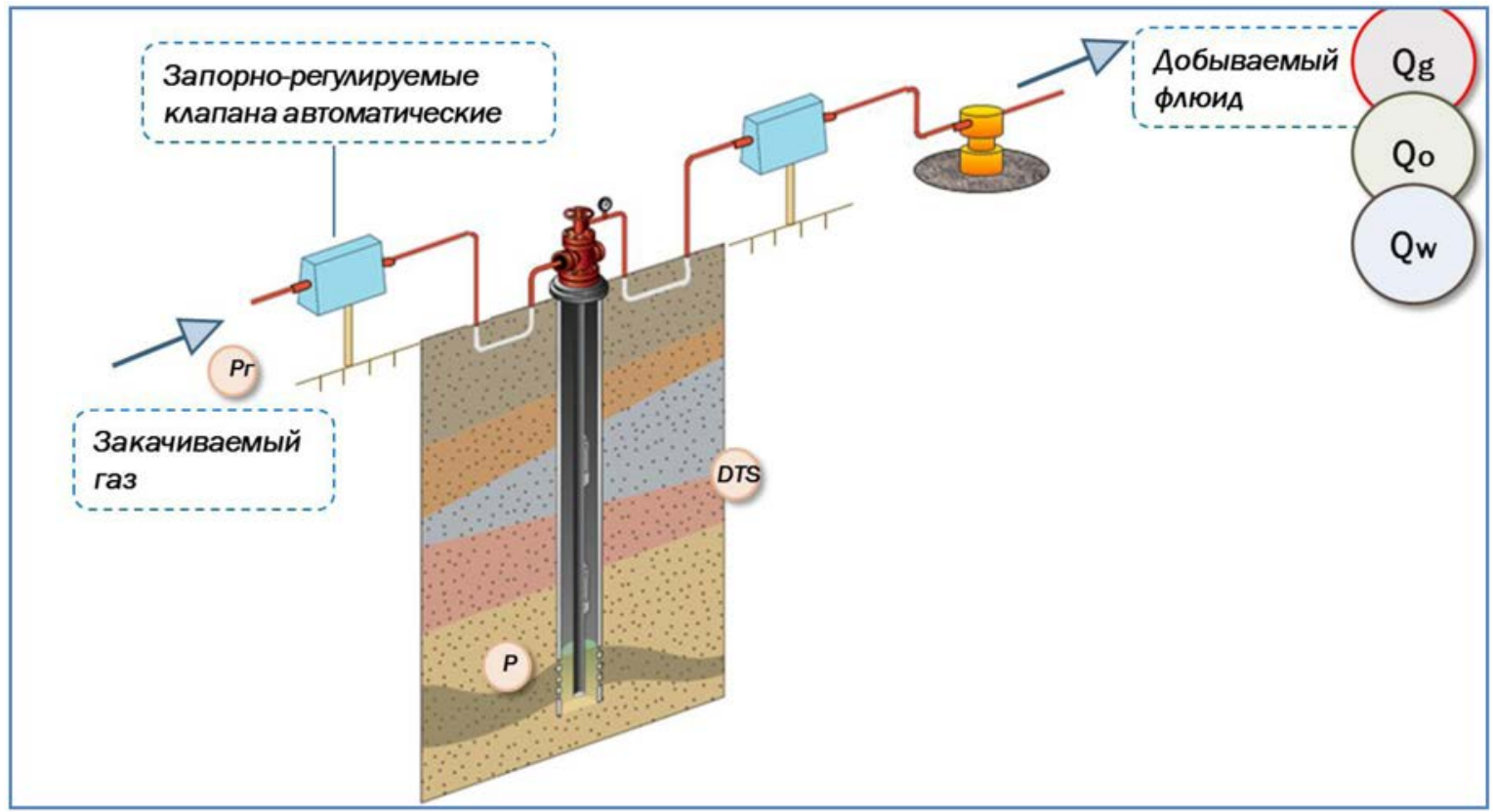

Figure 13-The concept of control and automation of the gas-lift well

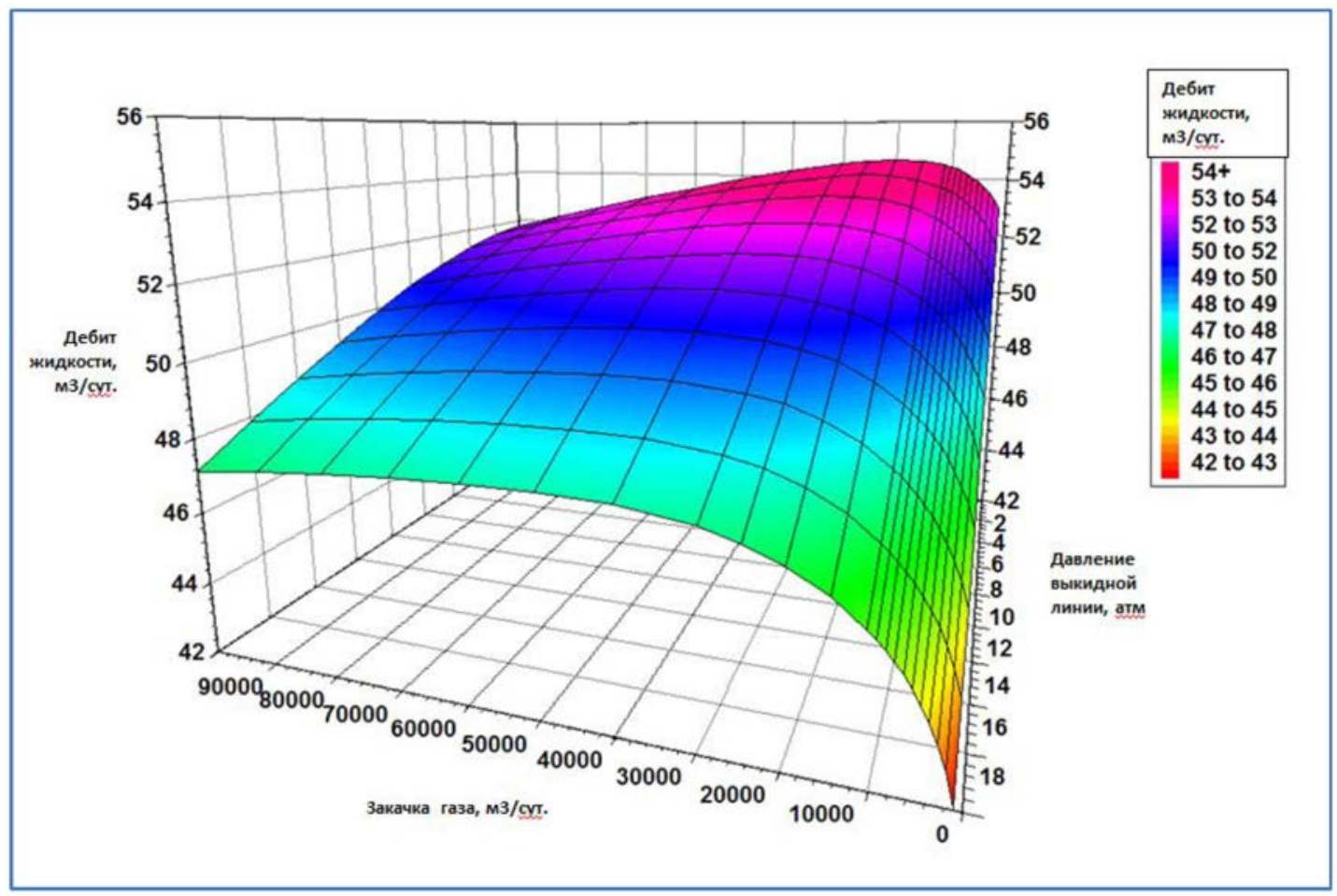

Figure 14-The dependence of the flow rate of the gas injection and wellhead pressure

\section{Conclusion}

This paper describes an integrated approach to well operation optimizasion in the Orenburg oil and gas condensate field, which is characterized by the largest number of wells in Russia that are operated by gas lift. One of the key decisions of the project was the organization of a gas lift operation maintenance center, of which tasks were:

- gas lift design using nodal analysis for each well 
- recommendations for the well cleanup and flow regime

- analysis of testing data and well surveys during decommissioning

- characterization of a gas-lift well

- continuous monitoring of gas-lift well operation according to the developed process conditions

- search for "bottlenecks" in gas-lift gas supply systems and surface facilities.

A number of studies were conducted on the gas-lift wells of the Orenburg oil and gas condensate field, which allowed not only to characterize the work of the gas-lift wells and optimize the work of production wells, but also revealed a number of new requirements for improving the efficiency of gas-lift well testing.

\section{Reference}

1. Galyautdinov I.M., Cherepovitsyn A.E. Complex approach to the selection of well-candidates for conducting geological and technical measures (by the example of the Eastern section of the Orenburg OGCC) // Oil. Gas. Innovations. - 2017. - № 7. - p. 23 - 33

2. Trubavin S.N., Ulyanov V.V., Kibirev Ye.A., Rymarenko K.V., Bak V.S., Historin P.E., Nukhaev M.T. Results of the OPI for optimization of gas-lift operation wells at the Orenburg oil and gas condensate field / Exposure Oil Gas. - 2017. - № 5 (58), September. - with. 36-39.

3. Ulyanov Vladimir, Kuchurin Alexey, Kibirev Evgeny, Gryzunov Andrey, Bak Viktor, Rymarenko Konstantin, Nukhaev Marat, Dadakin Nikita / "SPD paper 191533

4. Aksenov, M., D. Lachugin, M. Nukhaev, K. Rymarenko, V. Telkov, L. Gaidukov, K. Vologodskiy, D. Khramov: SPE 165552 "Northen Siberia Illustration Based on Biggest Heavy Oil Project in Russia "// 2013

5. Shushakov A.A, N.M. Pavlechko, E.A. Kibirev, Ya.A. Burtsev, R.A. Khabibullin, V.V. Kuznetsov / "Optimizing gas lift wells with gas pumping systems" // Oil-industry journal \# 12, 2015 p. 68-70. 


\section{Appendix}

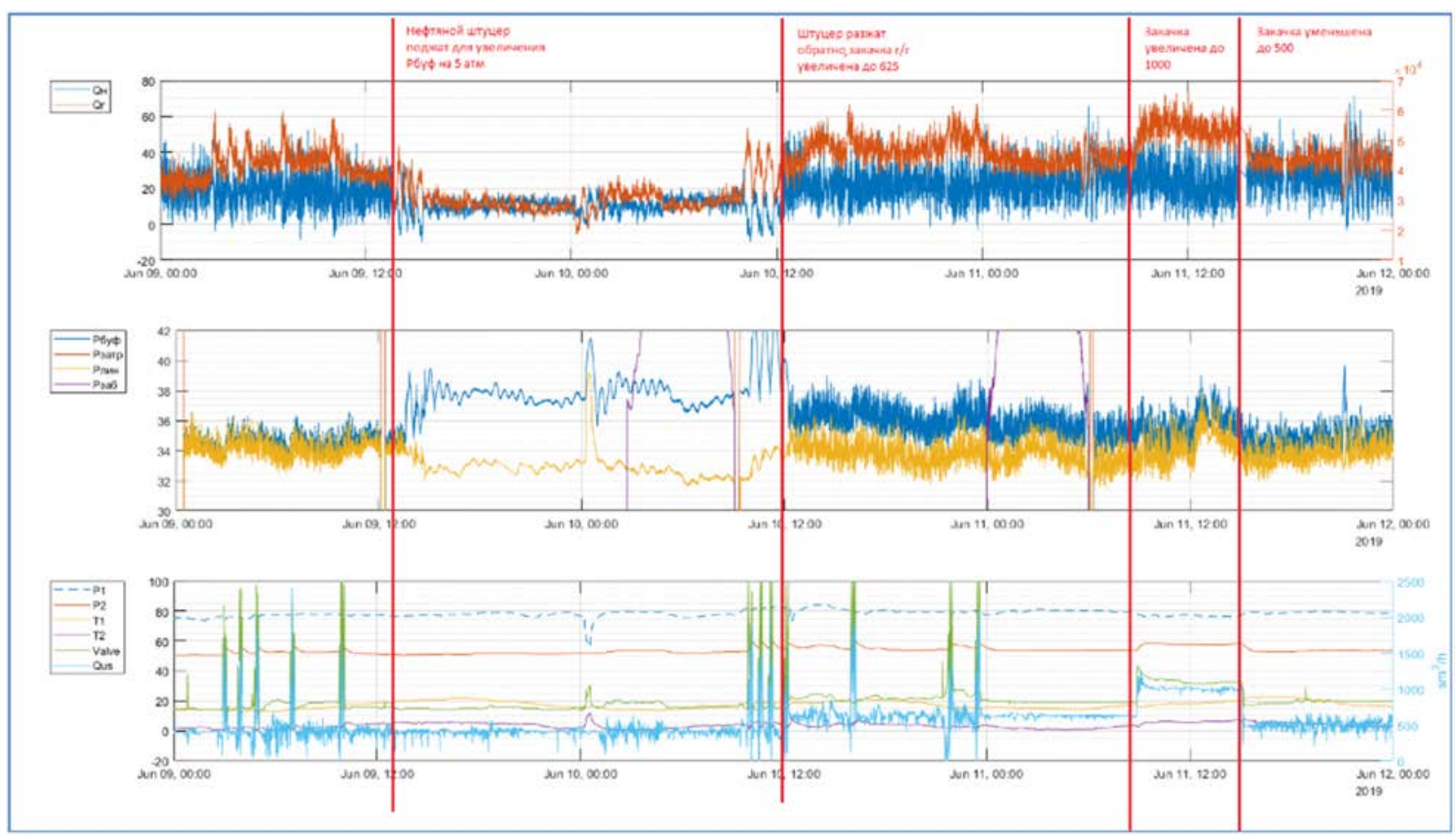

Figure A-1-The results of the gaslift well testing for 4 regimes 